\title{
Extraction, Characterization, and Application of Natural Dyes from the Fresh Mangosteen (Garcinia mangostana L.) Peel
}

\author{
Nita Kusumawati", Agus Budi Santoso*, Maria Monica Sianita ${ }^{\#}$, Supari Muslim* \\ ${ }^{\#}$ Department of Chemistry, Universitas Negeri Surabaya, Ketintang, Surabaya, 60231, Indonesia \\ E-mail: nkusumawati82@yahoo.com \\ *Department of Electrical Engineering, Universitas Negeri Surabaya, Ketintang, Surabaya, 60231, Indonesia \\ E-mail: suparimuslim@gmail.com
}

\begin{abstract}
This study is conducted to explore and utilize fresh mangosteen peel as an upcoming raw material for the production of natural dyes. The extract of fresh mangosteen peel is tested on cotton fabric by using alum as a mordanting agent who processed by pre-mordant dyeing procedure and fixation using 3 (three) different types of fixer. To obtain optimum interaction of fabric, mordant, dye and fixer, washing procedure has been performed using Turkish Red Oil (TRO) before the mordanting stage with varying washing time and repeated dyeing procedure with varying frequency of dyeing. As a result, the application of pre-mordanting dyeing method and fixation using iron (II) sulfate $\left(\mathrm{FeSO}_{4} \cdot 7 \mathrm{H}_{2} \mathrm{O}\right)$, alum $\left(\mathrm{KAI}\left(\mathrm{SO}_{4}\right)_{2} \cdot \mathbf{1 2}_{2} \mathrm{O}\right)$ and lime $(\mathrm{CaO})$, produced very good color from mangosteen peel dyes extract. Cotton fabric that has been through the pre-mordanting dyeing procedure using dyes extract of mangosteen peel consecutively bring green, light brown, and dark brown color each on the fixation result using iron (II) sulfate, alum, and lime. Preliminary evaluation and instrumentation allow us to determine whether the application of washing time varies, the repeated frequency of immersion and the use of different fixers compound using dyes extract with similar concentration and dyeing procedure affect the color intensity of the fabric sample.
\end{abstract}

Keywords — natural dyes; Garcinia mangostana Linn; pre-mordanting; fixer

\section{INTRODUCTION}

As more people realize the effect of synthetic dyes on the environment, the extraction process of dye compounds from natural sources, mainly plants, has become an important alternative to be used by textile industry [1]-[2]. Natural dyes are known to be biodegradable, non-toxic and generally, have a higher compatibility with environment compared to synthetic dyes [2]-[3]. Therefore, the utilization many varieties of a plant as raw material for natural dye, which focuses on the regeneration of waste and eco-friendly materials has begun to be recognized and applied in many textile products [2]-[4]. Colors that are achieved are mostly in pastel shades and commonly considered as soothing and pleasing to the eyes [2]-[5].

Mangosteen, also famous bamboo and phoenix fruits. Lycian originating in India and Malaysia [6], mainly in Thailand, Vietnam, the Philippines and other Southeast Asian countries, in China's Yunnan, Guangxi, Guangdong, Fujian and other places also have planted, such as Indonesia [7]-[8]. The suitable climate with annual rainfall that exceeds the evaporation rate and temperature has created suitable soil formations for these plants to grow.

Mangosteen peel is an ingredient of plant origin that was developed for the production of natural dyes in Malaysia [6] and Indonesia [9] because this material contains a lot of anthocyanin compounds [10]-[11] which produces a red color, and tannin [12] which produces a brown color. However, there is no optimization and standardization preparation and application procedures of mangosteen dyes extract for cotton dyeing. Reference [2] only show the standardization on preparation and application of mangosteen peel dyes extract on silk fabrics which are known to have better color reception than any other type of fabric. Basitah's research results in reference [2] show the potential benefits of mangosteen peel as a producer of brown, red, and purple color on silk fabric, through the process of pre-mordanting, simultaneous and post-mordanting dyeing method. In addition, the same reference also showed higher fastness of colors produced by the mangosteen peel extract to light and washing. Therefore, based on potential benefits of mangosteen peel dyes extract and dominance of cotton fabric as a base material in textile production all over the world, it is important to do a research about optimization and 
standardization of preparation and application procedures of mangosteen peel dyes extract in textile products made of cotton.

The purpose of this research was to explore and exploit the fresh mangosteen peels which considered as waste as an upcoming raw material for the production of natural dyes. Improved quality and color intensity generated from the application of mangosteen peel dyes extract conducted through the optimization of washing time, dyeing frequency and utilization of iron (II) sulfate, alum and lime as a color locking compound. The success of the mangosteen peel waste utilizing as natural dyes material for textile products, especially those made from cotton, will bring two positive impacts at once, namely reduced the quantity of organic waste resulting from consumption of mangosteen and simultaneously reduced the quantity of synthetic dyes waste as a by-product of the textile production.

\section{MATERIAL AND METHOD}

\section{A. Material}

The selection of mangosteen which is used as the main color producing material in this research is based on three important criteria: 1) quality (physical characteristics); 2) the quantity of the harvest with similar quality and harvest time related, and 3) the shelf life of fruit. The good quality fruit, in large quantities, must be considered to ensure that only the consistent amounts of fresh fruits are used for each experiment. Meanwhile, the shelf life of mangosteens become one of the important criteria to ensure that no significant changes in the content of anthocyanin and tannins pigments in a short period of time [2].

\section{B. Extract Preparation}

The peels are washed and then cut into small pieces using Philips HR7627 food processor with speed level on scale 2. The puree of mangosteen peel obtained from destruction process using a chopper is gathered in one place. The process continued by adding 1 liter of distilled water into 100 grams puree. The extraction of the mangosteen peel conducted through a heating process using NESCO Lab MS$\mathrm{H} 280$ Pro hot plate at a temperature of $100{ }^{\circ} \mathrm{C}$ to obtain the extract solution with a half volume of the initial volume. To obtain optimal dyeing results, the extract solution is filtered to get the aqueous solutions (see Fig. 1). The aqueous solution of the dyes extracts directly used in the dyeing process of cotton fabric samples.

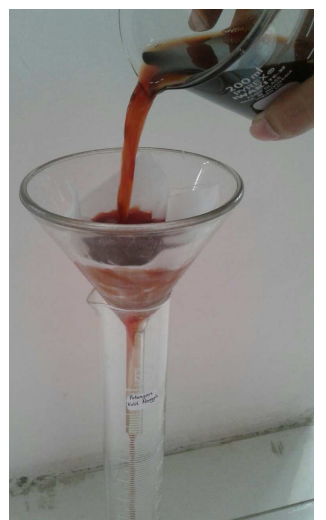

Fig. 1 A filtration process to obtain the extracts

\section{Washing Procedure}

Fabric samples to be dyed must through a washing process prior. The washing process is intended to remove contaminants that interact with the fabric fiber in order to increase the attractiveness of the mordant compounds towards fabric fibers. The fabric sample washing process conducted under the following procedures. The cotton fabric which is used as a sample for dyeing conditioned with a weight of 2.57 grams. Furthermore, samples of textile material to be dyed, immersed in a solution of 2 grams/liter TRO (Turkey Red Oil). The immersing process is carried out for 2 hours. Afterward, the material is rinsed with distilled water and wind dried. The same procedure was also applied for 4 hours and 6 hours washing time [13]-[14].

\section{Mordanting Procedure}

After the washing process using TRO, cotton fabric samples must through the mordanting stages using alum and soda ash $\left(\mathrm{Na}_{2} \mathrm{CO}_{3}\right)$. A mordanting solution prepared by dissolving 8 grams of alum and 2 grams of soda ash in every 1 liter of water used. To ensure the homogeneous solution is formed, the solution is stirred using magnetic stirrer until completely dissolved. The solution is heated using a hot plate to boiling, then loaded with 2.57-gram sample of fabrics while kept heated up for 1 hour. After that, the heating is stopped and the fabric sample left to immerse in the solution overnight. Having immersed overnight in the solution, the fabric sample is removed and rinsed (do not squeeze out), then dried and ironed. After the entire process is undertaken, samples of fabrics have been ready to dye using natural dyes [13]-[14].

\section{E. Dyeing Procedure}

After the sample of cotton fabrics are processed with the pre-mordanting method using alum to provide intermediate compounds for the interaction between fabrics fiber with dyes compound contained in the mangosteen peel extract, a sample of the fabric is ready to be processed using mangosteen peel dyes extract. Table 1 specifies the conditions for its preparation.

TABLE I

THE FORMULATION FOR DYEING COTTON (SAMPLES)

\begin{tabular}{|l|l|}
\hline Preparation & Condition \\
\hline Material to liquor & $1 / 35$ (gram $/ \mathrm{mL})$ \\
\hline Temperature & Room temperature \\
\hline Weight of the fabric's sample & 0.85 gram \\
\hline Dyeing time & 30 minutes \\
\hline
\end{tabular}

\section{F. Fixation Procedure}

On the dyeing process with natural dyes is needed a process of fixation, i.e. the color locking process which is done after dyeing process to obtain a good fade resistance. There are three types of commonly used fixer solution, which is iron (II) sulfate, alum, and lime. The making of fixer solution is done through stages where each as much as 50 grams of fixer solid compounds dissolved in 1 liter of water. The solution was left to precipitate out, and then take the transparent solution. Further, samples of cotton fabric are inserted into the fixer solution: (a) iron (II) sulfate, (b) alum and/or (c) lime. Fabric samples then processed in the fixer 
solution for 10 minutes. To determine differences in color produced by each fixer solution conducted the fixation process with 0.85 -gram sample of each fabric in $30 \mathrm{~mL}$ of iron (II) sulfate, alum and lime solution. The whole fabric samples subsequently rinsed and dried. In general, almost any types of natural dyes capable to dyeing silk well, but not with cotton materials.

\section{G. Colour Measurement and Characterization}

To investigate the characteristics of dye compounds contained in the aqueous extract of the mangosteen peel dyes solution has done an analysis of the wavelength region where an aqueous extract of mangosteen peel dyes absorbs electromagnetic waves with optimum, using Pharmaspec UV-1700 UV-Visible Spectrophotometer. The maximum wavelength region ( $\lambda$ maks) produced can provide information of dyes compounds there are dominant in aqueous dye extracts resulting from mangosteen peel. Meanwhile, an analysis of the color intensity from fabric samples is done in order to know the changes that occur as a result of the application of the washing process with timevarying, dyeing frequency as well as the use of three different types of fixer compounds. The color intensity analysis is done by using Shimadzu Diffuse Reflectant Ultraviolet (DRUV) Spectrophotometer UV-2401-PC instrument. In general, the higher color intensity will produce lower reflectance percentage in the DRUV result.

\section{RESULTS AND DISCUSSION}

\section{A. The Effect of Washing Time and Fixer Compound Type} to Color Intensity Produced

Mangosteen peels contain a number of pigment that comes from two metabolites, namely mangostin and $\beta$ mangostin. If all of the content contained in the mangosteen fruit is extracted, will be obtained natural dye in the form of anthocyanins which generally produces red, purple, and blue colors. Mangosteen peels also contain flavan-3,4-diols, which classified as tannin compounds and can be used as natural dyes on fabric. Fig. 2 shows the molecular structure of anthocyanin compounds, whereas the molecular structure of tannin shown in Fig. 3. Meanwhile, Fig. 4 and Fig. 5 shows the interactions that occur between the fabric fiber, mordant compounds, anthocyanins and tannins dye compounds with three types of fixer used.

The dyeing process on cotton fabric samples with premordanting dyeing method using dyes extracts of mangosteen peels material that ends with fixation using iron (II) sulfate, alum, and lime, each produces a dark green, light brown and dark brown.<smiles>COc1cc2c(O)cc(O)cc2oc1=O</smiles>

Fig. 2 A molecular structure of anthocyanin

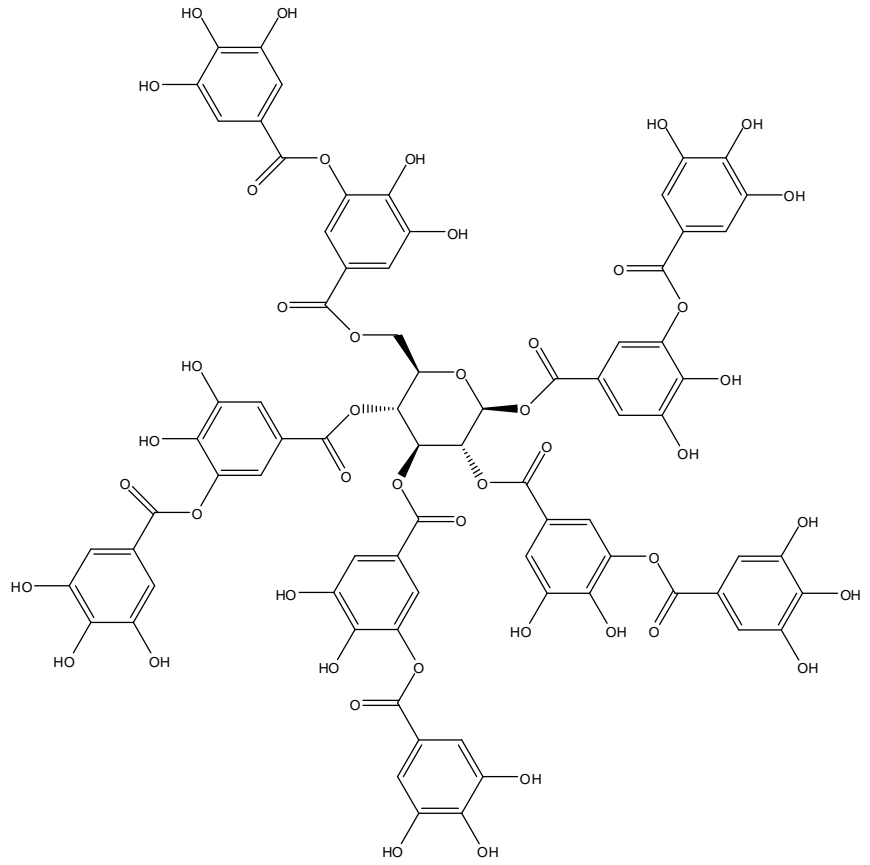

Fig. 3 A molecular structure of tannin

The dyeing result using mangosteen peels material showed that each color intensity generated from the fixation process using iron (II) sulfate, alum and lime will be progressively increased in line with the increasing of the washing time applied. This condition indicates that the dye compounds generated by mangosteen peels has a functional group with a positive charge similar to the functional groups of fabric fiber, so the existence of the mordant compounds will play a role in increasing the interaction that occurs between the fabric fiber and dye compounds. This fact also supported by the results of mangosteen peel dye compounds analysis, which has been done at this stage, showed that the mangosteen peel contains $0.22 \%$ yellow colored mangostin metabolites. Inside mangostin metabolites contain a wide variety of pigments of which the largest is anthocyanin and tannin. In accordance with the information of the molecular structure of anthocyanins and tannins, as it appears in Fig. 2 and Fig. 3, note that the reactive functional groups in anthocyanins were positively charged, while tannins compound dominated by negatively charged hydroxide functional groups. Table 2 shows the fabric samples reflectance percentage data that have been through the dyeing process with variations in the washing time and the type of fixer compound used. 


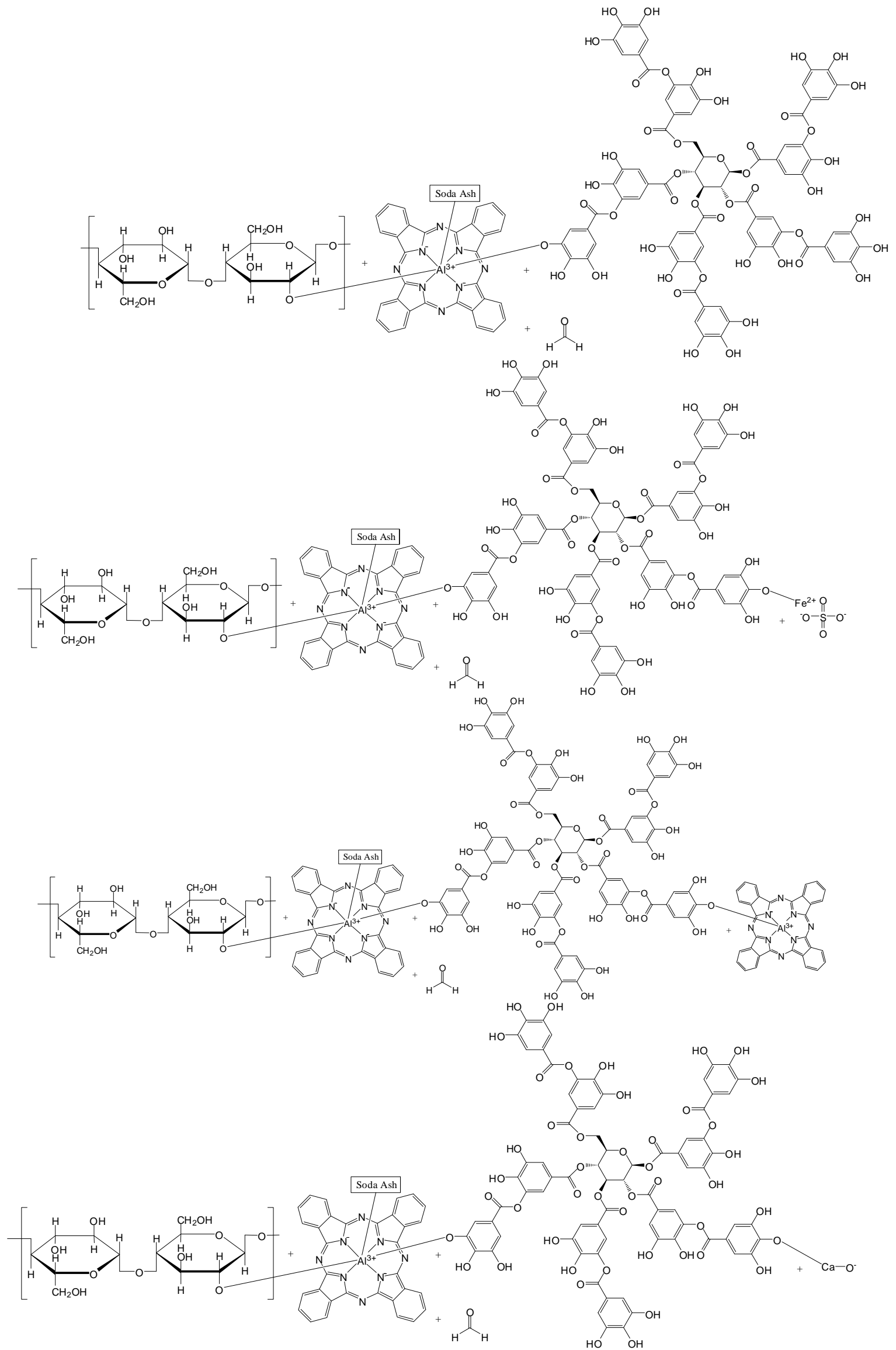

(a)

Fig. 4 Interaction between fabric fiber, mordant, tannin pigment dan iron (II) sulfate (a), alum (b), and lime (c) (hypothetic) 


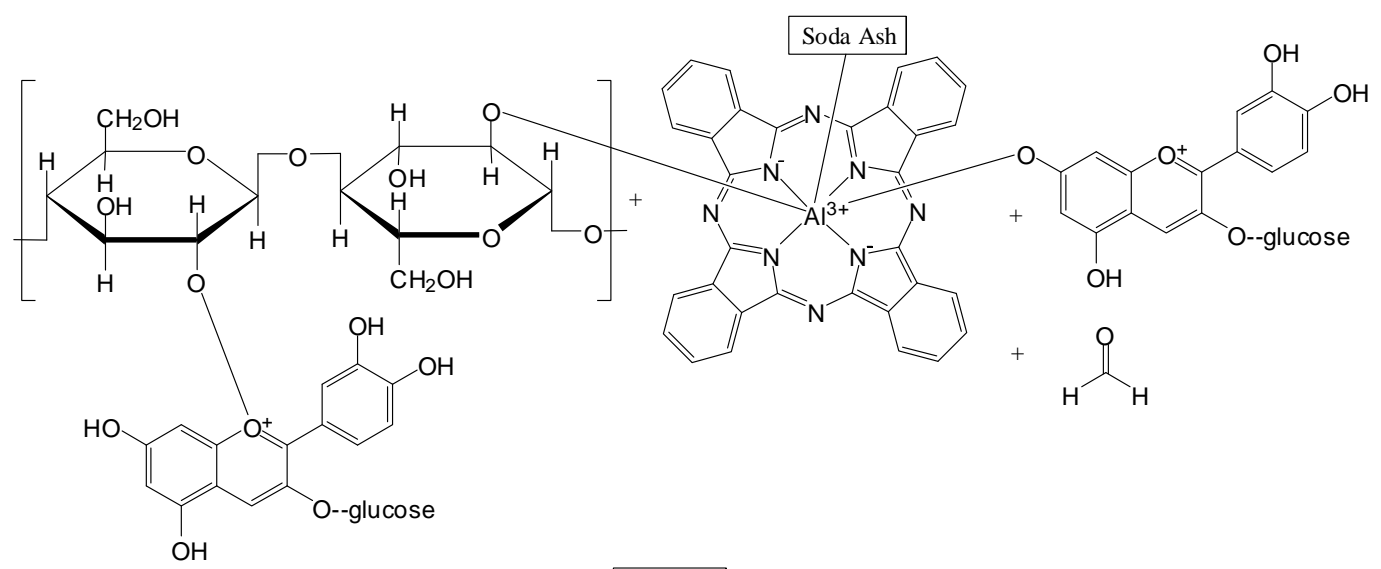

(a)

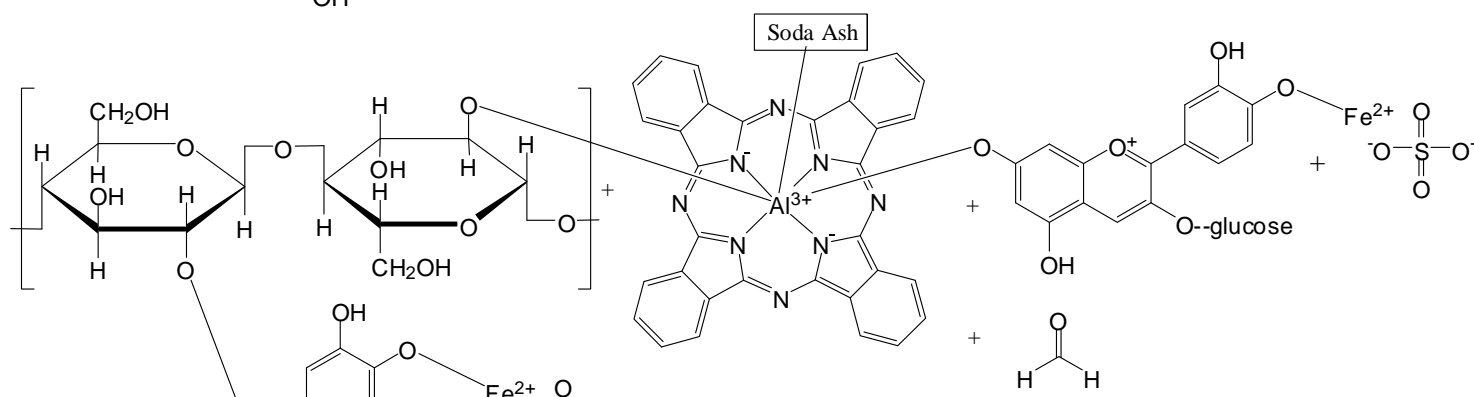

(b)

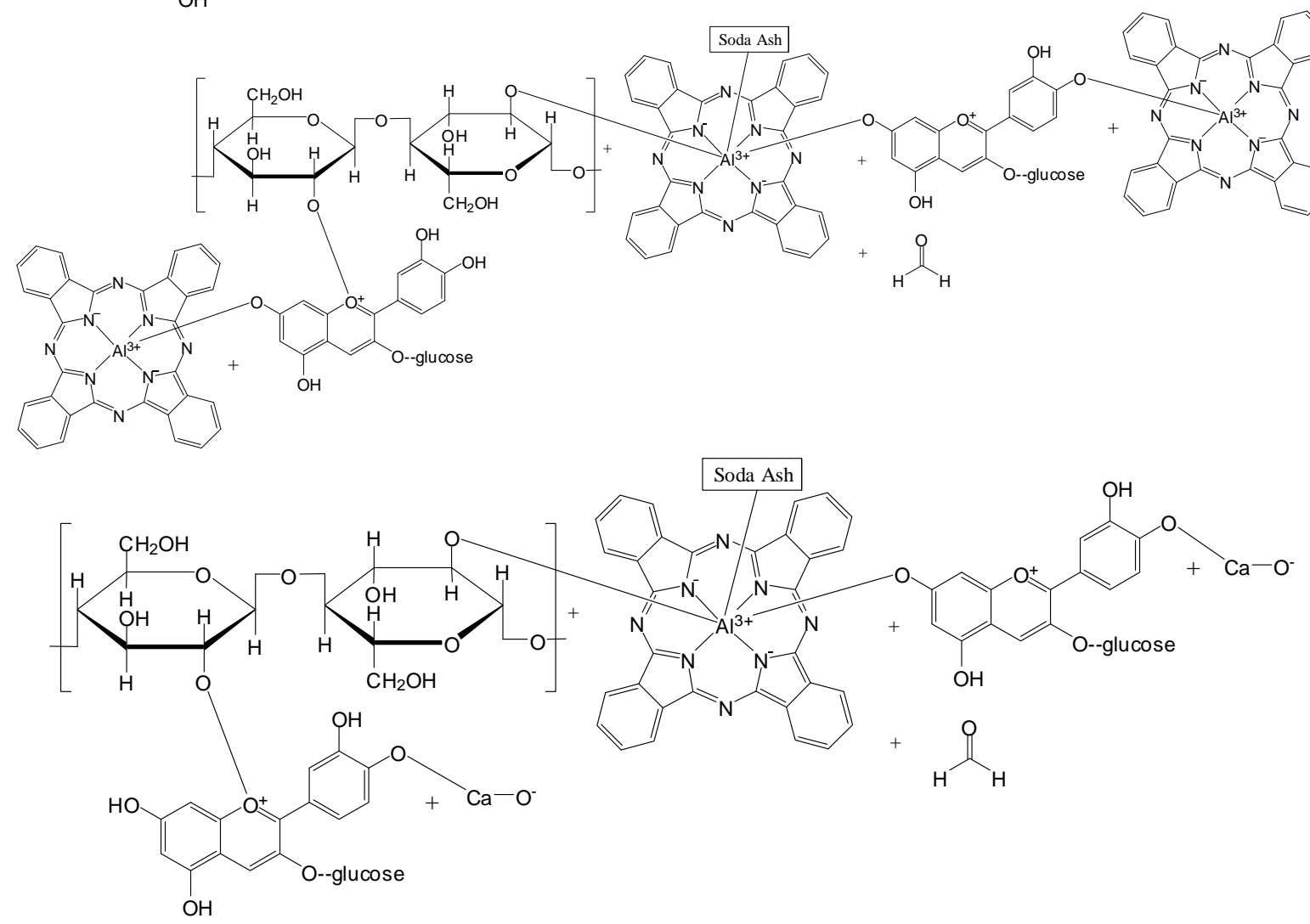

Fig. 5 Interaction between fabric fiber, mordant, anthocyanin pigment dan iron (II) sulfate, alum and lime (hypothetic)

Not only on the cotton samples through the mordanting process, on a control fabric sample that does not through the mordanting process also shows the emergence of similar color although the color intensity is not as high as the one the color intensity of the fabric samples that through the mordanting process. This is caused by the presence of contaminant compounds which has similar functional groups with a mordant compound and provide intermediary 
interaction between fabric fiber with a dyes compound. However, the dyeing results that occurs through these interactions won't last long or have high fade resistance, especially when the fabric samples through a washing process that allows contaminants solubility in the wash water.

In Fig. 4 appears that mordant compound, in this case, is an alum, has acted as an intermediary compound or a bridge for interaction between the fabric fibers and tannin dyes compound. The aluminum atom that has a charge of $3+$ have been interacting as a whole, each with fiber fabric, dyes compounds contained in mangosteen peel extract and soda ash. To increase the color fastness has done color locking using three kinds of fixer compounds. The interaction in Fig. 5 shows that the positive charge of the iron (II) sulfate fixer compound will interact with the negative charge from functional groups contained in the dye compound in mangosteen peel extract. Interactions that also common at this dyeing stage, which ended with the fixation process using alum and lime fixer compound, in which the positive charge from the aluminium as central atom in the alum compounds and the positive charge of the $\mathrm{Ca}$ atom on lime compounds will interact with the negative charge from hydroxyl functional groups contained in the dye compound.

Inconsistent with this interaction, in Fig. 5 shows that the existence of mordant compound which has a positive charge on its central atom has to block the interaction that may occur between the positively charged anthocyanin pigments with the fabric fiber. No detection of red color emergence in cotton fabric samples that have been through the dyeing process using mangosteen peel extract showed the dominance of tannin dye compound on the interaction established between the fabric fiber, mordant, dyes, and fixer compound. This is due to higher negative charge atmosphere that exists in the tannin compound, making it more reactive to a mordant compound which in this case acts as intermediary compound between fabrics fiber and dyes, compared to anthocyanin dye compound.

TABLE II

REFlectance Percentage Data of Fabric SAMPLes From Dyeing PROCESS WITH DIFFERENT TIME WASHING AND FIXER TYPE

\begin{tabular}{|l|l|l|l|}
\hline No & $\begin{array}{l}\text { Washing } \\
\text { Time } \\
\text { (hour) }\end{array}$ & Fixer Type & $\begin{array}{l}\text { Reflectance } \\
(\boldsymbol{\%})\end{array}$ \\
\hline 1 & 0 & Iron (II) sulfate & 18.92 \\
\hline 2 & 2 & Iron (II) sulfate & 16.44 \\
\hline 3 & 4 & Iron (II) sulfate & 12.45 \\
\hline 4 & 6 & Iron (II) sulfate & 9.85 \\
\hline 5 & 0 & Alum & 52.88 \\
\hline 6 & 2 & Alum & 40.92 \\
\hline 7 & 4 & Alum & 40.77 \\
\hline 8 & 6 & Alum & 38.44 \\
\hline 9 & 0 & Lime & 24.41 \\
\hline 10 & 2 & Lime & 21.10 \\
\hline 11 & 4 & Lime & 19.61 \\
\hline 12 & 6 & Lime & 15.11 \\
\hline
\end{tabular}

The reflectance percentage data of fabric samples dyeing process using anthocyanin and tannin dyes compound generated from the extraction process of mangosteen peel with water solvent, as shown in Table 2, shows that: (1) The fabric samples that fixed with iron (II) sulphate fixer compound has produced dark green color with a higher color intensity; (2) The fabric samples that fixed with alum has produced a light brown color with higher color intensity, and (3) The fabric samples that fixed with lime has produced a dark brown color with increased color intensity in line with the increasing washing time applied.

\section{B. The Effect of Dyeing Frequency and Fixer Type}

Variables Combination on Color Intensity Produced

Visual data of cotton fabric samples that have been through the dyeing process using dye extracts from mangosteen peel material with variations in the dyeing frequency and fixer compound type shows: (a) has detected an increase in the dark green color intensity that appears after fixation process using iron (II) sulfate fixer compound along with the higher frequency of dyeing process applied. This is because the optimal interaction between fabrics fiber, mordant, and also anthocyanins and tannins dyes compound along with the high frequency of dyeing applied; (b) has detected the appearance of yellow color on control fabric samples which fixated using alum fixer and the appearance of light brown color on fabric samples that has been through a washing process for 6 hours. The emergence of yellow color (different colors) in control fabric samples is possible because in control fabric samples interactions that occur is not between fabric fiber, mordant, anthocyanin, and tannin dye compounds and alum fixer compounds but between the fabric fiber, contaminant, anthocyanin, and tannin dye compounds and alum fixer compounds. The different types of interactions will lead to different electronic transitions and will automatically bring up a different color in accordance with chromophore contained in the final product; (c) has been detected the emergence of a brown color with higher color intensity (darker color) on the fabric sample fixated using lime fixer along with the high dyeing frequency applied. Similar to the results of fixation using compounds of iron (II) sulfate and alum, darker brown color has been detected along with the high frequency of dyeing, also due to an optimum interaction that can occur between the fabric fiber, mordant, and dye compound along with the high frequency of the dyeing applied.

TABLE III

Reflectance Percentage Data of Fabric Samples From Dyeing PROCESS WITH DIFFERENT DYEING FREQUENCY AND FIXER TYPE

\begin{tabular}{|l|l|l|l|}
\hline No & $\begin{array}{l}\text { Dyeing } \\
\text { Frequency } \\
\text { (times) }\end{array}$ & Fixer Type & $\begin{array}{l}\text { Reflectance } \\
(\%)\end{array}$ \\
\hline 1 & 1 & Iron (II) sulfate & 9.85 \\
\hline 2 & 5 & Iron (II) sulfate & 9.57 \\
\hline 3 & 10 & Iron (II) sulfate & 8.60 \\
\hline 4 & 1 & Alum & 38.44 \\
\hline 5 & 5 & Alum & 36.26 \\
\hline 6 & 10 & Alum & 16.17 \\
\hline 7 & 1 & Lime & 15.11 \\
\hline 8 & 5 & Lime & 14.82 \\
\hline 9 & 10 & Lime & 7.23 \\
\hline
\end{tabular}

In addition, the emergence of a different color in dyeing results using the mangosteen peel extract with different type of fixer is due to the creation of a different molecular structure in the final product of the interaction that occurs 
between the fabric fiber, mordant, dye, and iron (II) sulfate; fabric fiber, mordant, dye, and alum; and between fabric fiber, mordant, dye, and lime fixer compounds. The differences in the molecular structure will have an impact on different orbital types, electronic transitions and light absorption, which will automatically affect the different colors absorbed and forwarded by the molecule compounds in question.

\section{CONCLUSIONS}

An attempt to rediscover the natural dyes of the local Indonesian natural resources, mainly derived from plants, has been done. The consistent characteristics of extracted material and standardized operating conditions are an extremely important variable to eliminate the disparity of shades that are produced, especially in the dyeing process using natural dyes such as those resulting from mangosteen peel material. Therefore it is necessary to optimization a number of variables associated with the natural dyes preparation process and its application in the cotton fabric dyeing process. Experiment results indicate the emergence of three kinds of different colors as a result of the fixation process using compounds of iron (II) sulfate, alum, and lime, with an increasing in line with increasing washing time and dyeing frequency conducted. The dyeing process that involves the fixation process using iron (II) sulfate, alum and lime have led to the emergence of the dark green, light brown and dark brown colors on cotton fabric samples. Meanwhile, the optimization the washing time and dyeing frequency shows the decreasing reflectance percentage, which is in the range: $52.88 \%-9.85 \%$ in line to the increasing color intensity of cotton fabric samples with washing time for 1 - 3 minutes; and $38.44 \%-7.23 \%$ of cotton fabric samples that have been through dyeing process that repeated 5 and 10 times.

The whole process will pave the way for the invention of a new type of natural dye that can be produced through a number of stages in an experiment that systematic and wellstructured.

\section{ACKNOWLEDGMENT}

We would like to thank Direktorat Penelitian dan Pengabdian Masyakarat Kementerian Riset dan Teknologi Pendidikan Tinggi Republik Indonesia which has provided financial support through National Priority Research Program Masterplan of Acceleration and Expansion of Indonesia Economic Development.

\section{REFERENCES}

[1] H.T. Deo and B.K Desai, "Dyeing of Cotton and Jute with tea as a natural dye," Colouration Technol, vol. 117, pp. 7-8, 1999.

[2] T. Basitah,'Extraction, Characterization, and application of natural dyes from the fresh rind of index color 5 mangosteens (Garcinia mangostana L.)," International Journal of Chemical, Molecular, Nuclear, Materials andMetallurgical Engineering. Vol. 9, no. 7, pp. 871-874, 2015.

[3] Z. Maria, N. Eleni, V. Evangelia, T. Eforia, "Colour and fastness of natural dyes: revival of traditional dyeing techniques," Colouration Technol, vol. 127, pp. 18-27, 2010.C.

[4] Colchester, A Textiles Today: A Global Survey of Trends and Traditions. United Kingdom: Thames \& Hudson Ltd, 2007.

[5] Azah Aziz, Warna mengerna. Rupa dan Gaya: Busana Melayu. Bangi: Universiti Kebangsaan Malaysia, 2006.

[6] S. Nieuwolt, Introduction: The importance of climate in agricultural planning. Climate and Agricultural Planning in Peninsular Malaysia. Serdang: Unit Percetakan MARDI, 1982.

[7] Y. Zhicheng and L. Wenfeng, "Preparation method of mangosteen shell natural dye, application, and staining method thereof," $\mathrm{CN}$ 103483855 B, June 17, 2015.

[8] E. Mansyah, I. Muas, M.Jawal A.S., and Affandi, "The research for supporting sustainable Mangosteen (Garcinia mangostana L.) production", International Journal of Advanced Science, Engineering, and Information Technology, vol. 3, no. 1, pp. 16.

[9] R. Farida dan F.C. Nisa, "Ekstraksi antosianin limbah kulit manggis metode microwave assisted extraction (lama ekstraksi dan rasio bahan: pelarut)", Jurnal Pangan dan Agroindustri, vol. 3, no. 2, pp. 362-373, 2015.

[10] M. Chairat, J.B. Bremner, and K. Chantrapromma, "Dyeing of cotton and silk yarn with the extracted dye from the fruit hull of mangosteen, Garcinia mangostana Linn," Journal of Fibers and Polymers, vol. 8, no. 6, pp. 613-619, 2007.

[11] R.A. Fadri, Salvia, S.K. Putri, Evawati, R. Novita, R. Hasniyati, "Secure/safe, healthy, intact and halal of Mangosteen small medium enterprise," International Journal of Advanced Science, Engineering, and Information Technology, vol. 5, no. 3, pp. 242.

[12] A.C. Dweck, Dweck Data. [Online]. Available http://www.dweckdata.co.uk/Published_papers/Garcinia_mangostana. pdf

[13] N. Kusumawati, T. Koestiari, A.B. Santoso, "The influence of washing process using TRO on indigosol dyeing quality, leaching percentage, and mechanical strength of mori fabric," Res. J. Pharm., Biol. Chem. Sci, vol. 6, no. 6, pp. 55-63, 2015.

[14] N. Kusumawati, S. Muslim, A. Kistyanto, "Operational conditions optimization on blacu fabric dyeing technology. Case study: mordanting influence on naphtol color quality and mechanical strength of blacu fiber," Res. J. Pharm., Biol. Chem. Sci, vol. 7, no. 5, pp. 55-63, 2016. 